\title{
SEISMIC RESPONSE OF REINFORCED CONCRETE STRUCTURE BY USING DIFFERENT BRACING SYSTEMS
}

\author{
Umesh.R.Biradar ${ }^{1}$, Shivaraj Mangalgi ${ }^{2}$ \\ ${ }^{1}$ P.G Student of structural Engineering, Department of Civil Engineering, Poojya Doddappa Appa College of \\ Engineering, Gulbarga-585102 \\ ${ }^{2}$ Associate Prof. Department of Civil Engineering, Poojya Doddappa Appa College of Engineering, Gulbarga-585102
}

\begin{abstract}
Bracings systems are one of the lateral load resisting system which has got structural importance specially in reinforced concrete buildings. Different bracing systems are efficient enough for seismic responses. To know the importance of different bracing systems in multistorey RC frame structure. 7 models with different bracing systems have been modeled and analysed for linear static(ESA), linear dynamic(RSA), non linear static(Pushover Analysis) and non linear dynamic analysis(Time history Analysis) by ETABS software .Results such as fundamental time period, seicmic base shear, storey displacement and storey drift have been evaluated and compared with bare frame model. Model 2 (X bracing system) is showing better seismic performance out of all the models.
\end{abstract}

Keywords: - Earthquake, Bare Frame, Bracings, ETABS

\section{INTRODUCTION}

Seismic Analysis is a subset of structural analysis and is the calculation of the response of a building structure to earthquakes It is part of the process of structural design, earthquake engineering or structural assessment and retrofit in regions where earthquakes are prevalent. In order to make multi-storey structures stronger and stiffer, which are more susceptible to earthquake and wind forces, the cross sections of the member increases from top to bottom this makes the structure uneconomical owing to safety of structure .The behavior of the buildings during earthquake depends not only on the size of the members and amount of reinforcement, but to a great extent on the placing and detailing of the reinforcement Therefore, it is necessary to provide special mechanism that to improve lateral stability of the structure.

Bracing systems are used to resist horizontal forces(wind load, seismic action) and to transmit to the foundation. The bracing members are arranged in many forms, which carry solely tension, or alternatively tension and compression...Such systems reduces bending moment and shear force in the columns.

Bracings hold the structure stable by transferring the loads sideways(not gravity, but wind or earthquake loads)down to the ground and are used to resist lateral loads, there by preventing sway of the structure. Diagonal braces are efficient elements for developing stiffness and resistance to wind loads. There are different types of bracing systems in common use such as single diagonal bracing, $\mathrm{X}$ bracing, $\mathrm{V}$ bracing, $\mathrm{K}$ bracing, inverted $\mathrm{V}$ bracing.

The main aim of the present study is to know the effect of bracings on the multistory RC frames. How the different types of bracings enhance the overall performance of the building and to identify the suitable bracing system for resisting the seismic load efficiently.

\section{DESCRIPTION OF STRUCTURAL MODELS}

The study has done on 7 different models of an eleven(11) storey building are modeled.The building has five bays in $\mathrm{X}$ direction and five bays in $\mathrm{Y}$ direction with the plan dimension $(25 \mathrm{~m} \times 20 \mathrm{~m})$ having beam size $(0.35 \mathrm{~m} \times$ $0.5 \mathrm{~m})$, column size $(0.45 \mathrm{~m} \times 0.9 \mathrm{~m})$, thickness of Slab is $0.120 \mathrm{~m}$, bracings of $(0.20 \times 0.20 \mathrm{~m})$ and a storey height of 3.5 $\mathrm{m}$ each in all the floors. The building is kept symmetric in both mutually perpendicular directions in plan to avoid torsional effects. The orientation and size of column is kept same throughout the height of the structure. The building is considered to be located in seismic zone V. The building is founded on medium strength soil. Response reduction factor for the special moment resisting frame has taken as 5.0. The unit weights of concrete are taken as $25.0 \mathrm{KN} / \mathrm{m}^{3}$ the floor finish on the floors is $1.5 \mathrm{KN} / \mathrm{m}^{2}$. The live load on floor is taken as $3.5 \mathrm{KN} / \mathrm{m}^{2}$. In seismic weight calculations, $50 \%$ of the floor live loads are considered.

\section{ANALYTICAL MODEL CONSIDERED FOR} ANALYSIS

Model 1: Building modeled as bare frame. However, masses of the walls are included.

Model 2: Building has RC X bracings in outrigger patterns in the middle Bay in every storey in all the four sides. 
Model 3:. Building has RC inverted V (chevron) in outrigger patterns in the middle Bay in every storey in all the four sides.

Model 4: Building has RC V bracings in outrigger patterns in the middle Bay in every storey in all the four sides.
Model 6: Building has RC backward diagonal bracings $(\backslash)$ in outrigger patterns in the middle stories in all four sides.

Model 7: Building has RC K bracings in outrigger patterns in the middle stories in all four sides.

Model 5: Building has RC forward diagonal bracings(/) in outrigger patterns in the middle stories in all four sides.

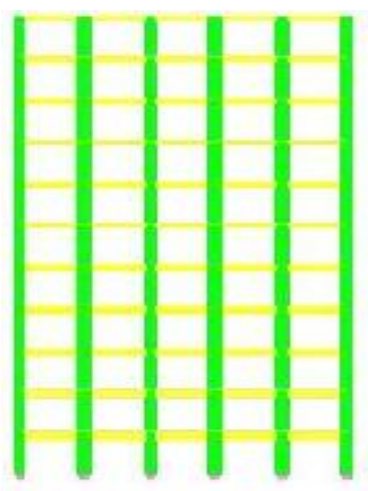

MODEL 1

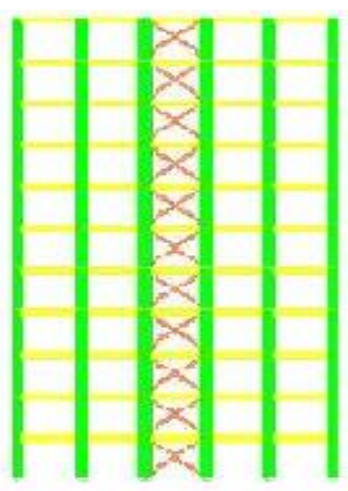

MODEL 2

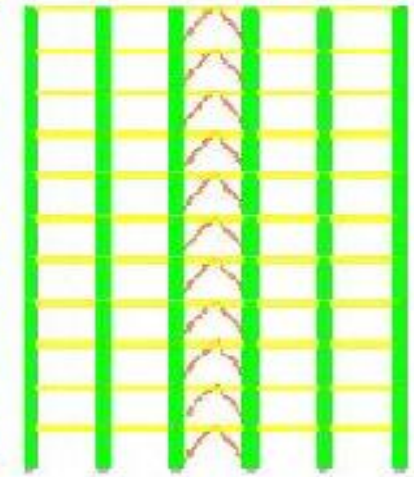

MODEL 3

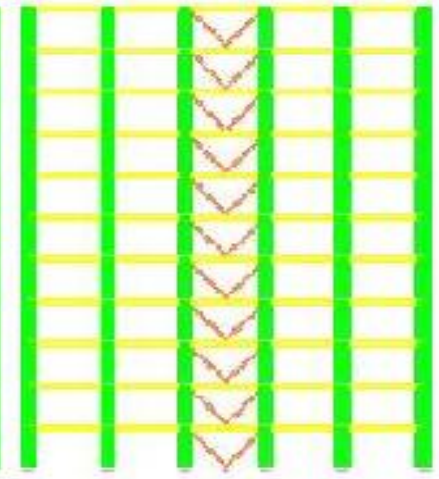

MODEL 4

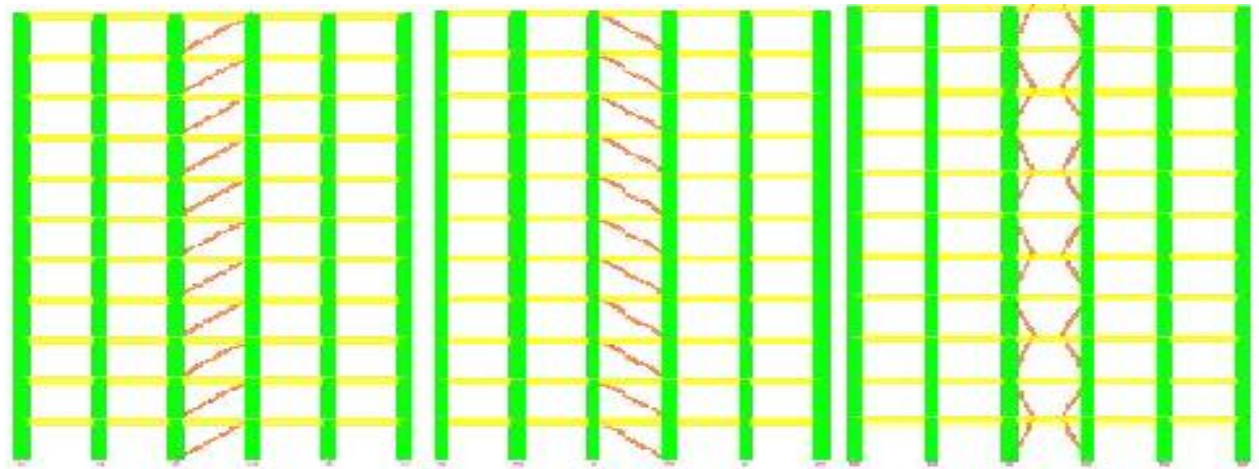

MODEL 5

MODEL 6

MODEL 7

Fig 1 Elevation of various building models

\section{RESULTS AND DISCUSSION}

In this paper the results of all the building models are presented. Analysis were carried out using ETABS and different parameters studied such as Fundamental natural time period, Base shear, storey displacement and storey drifts, the tables and figures are shown below.

Table 1: Comparison of time period between IS code and ETAB

\begin{tabular}{|l|l|l|l|l|}
\hline & \multicolumn{2}{|l|}{ IS CODE Method } & \multicolumn{2}{l|}{ ETABS Analysis } \\
\hline $\begin{array}{l}\text { Mo } \\
\text { del } \\
\text { No }\end{array}$ & $\begin{array}{l}\text { Longitu } \\
\text { dinal }\end{array}$ & $\begin{array}{l}\text { Transv } \\
\text { erse }\end{array}$ & $\begin{array}{l}\text { Longitu } \\
\text { dinal }\end{array}$ & $\begin{array}{l}\text { Transv } \\
\text { erse }\end{array}$ \\
\hline $\mathbf{1}$ & 1.159 & 1.159 & 1.8536 & 1.8536 \\
\hline $\mathbf{2}$ & 1.159 & 1.159 & 1.5664 & 1.5664 \\
\hline $\mathbf{3}$ & 1.159 & 1.159 & 1.6153 & 1.6153 \\
\hline $\mathbf{4}$ & 1.159 & 1.159 & 1.6438 & 1.6438 \\
\hline $\mathbf{5}$ & 1.159 & 1.159 & 1.6464 & 1.6464 \\
\hline $\mathbf{6}$ & 1.159 & 1.159 & 1.6464 & 1.6464 \\
\hline
\end{tabular}

\begin{tabular}{|l|l|l|l|l|}
\hline $\mathbf{7}$ & 1.159 & 1.159 & 1.7641 & 1.7641 \\
\hline
\end{tabular}

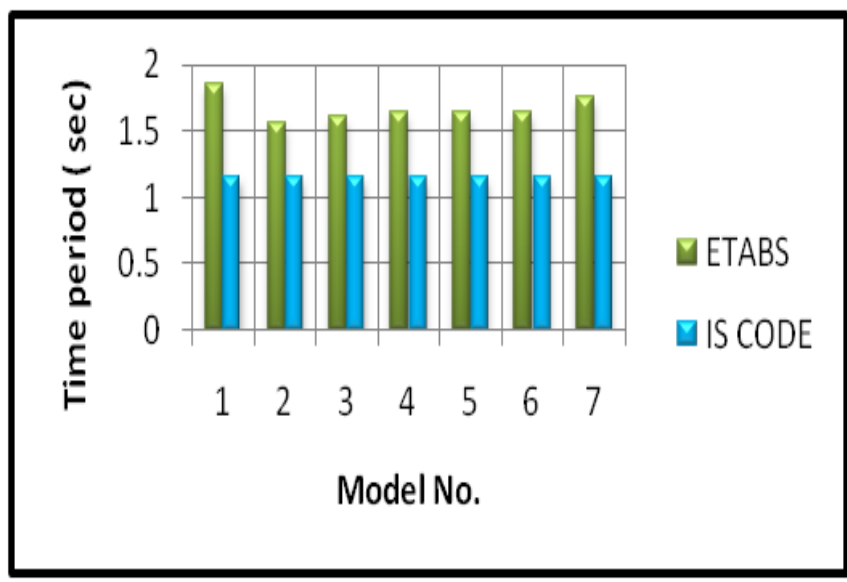

Fig 2: Model Vs Time period for different building model along longitudinal direction 
IS Code procedure does not give suitable guidelines or any empirical relationship to calculate fundamental natural time period for braced frame, it can be seen from table: 1 , IS Code gives same fundamental time period values for bare frame as well as braced. When the building models being analyzed in ETABS, the natural time period is increased by $37.47 \%$ as compared with IS Code method for bare frame (model 1).When different bracing system incorporated in the different building models, the reduction in fundamental natural time period are $15.49 \%, 12.87 \%, 11.32 \%, 11.17 \%$, $11.17 \%$ and $4.83 \%$ for Model2, Model3, Model4, Model5, Model6 and Model7.

Therefore bracings of different shapes considerably influence the overall performance of R.C framed structures.

Table 2: Comparison of Base shear with IS code, Linear static analysis and Response spectrum analysis for various building models

\begin{tabular}{|l|l|l|l|l|l|l|}
\hline \multicolumn{3}{|l}{ IS CODE Method } & \multicolumn{2}{l|}{ ESA (ETABS) } & RSA (ETABS) \\
\hline $\begin{array}{l}\text { Model } \\
\text { No }\end{array}$ & Longitudinal & Transverse & Longitudinal & Transverse & Longitudinal & Transverse \\
\hline $\mathbf{1}$ & 4195.782 & 4195.782 & 2790.53 & 2543.69 & 2425.48 & 2262.15 \\
\hline $\mathbf{2}$ & 4219.893 & 4219.893 & 3302.53 & 3024.94 & 2810.49 & 2660.01 \\
\hline $\mathbf{3}$ & 4211.025 & 4211.025 & 3246.58 & 2929.46 & 2769.3 & 2582.71 \\
\hline $\mathbf{4}$ & 4211.025 & 4211.025 & 3190.76 & 2878.7 & 2731.56 & 2548.57 \\
\hline $\mathbf{5}$ & 4207.126 & 4207.126 & 3133.24 & 2870.91 & 2686.38 & 2541.26 \\
\hline $\mathbf{6}$ & 4207.126 & 4207.126 & 3133.24 & 2870.91 & 2686.38 & 2541.26 \\
\hline $\mathbf{7}$ & 4209.501 & 4209.501 & 2927.06 & 2681.62 & 2524.23 & 2382.12 \\
\hline
\end{tabular}

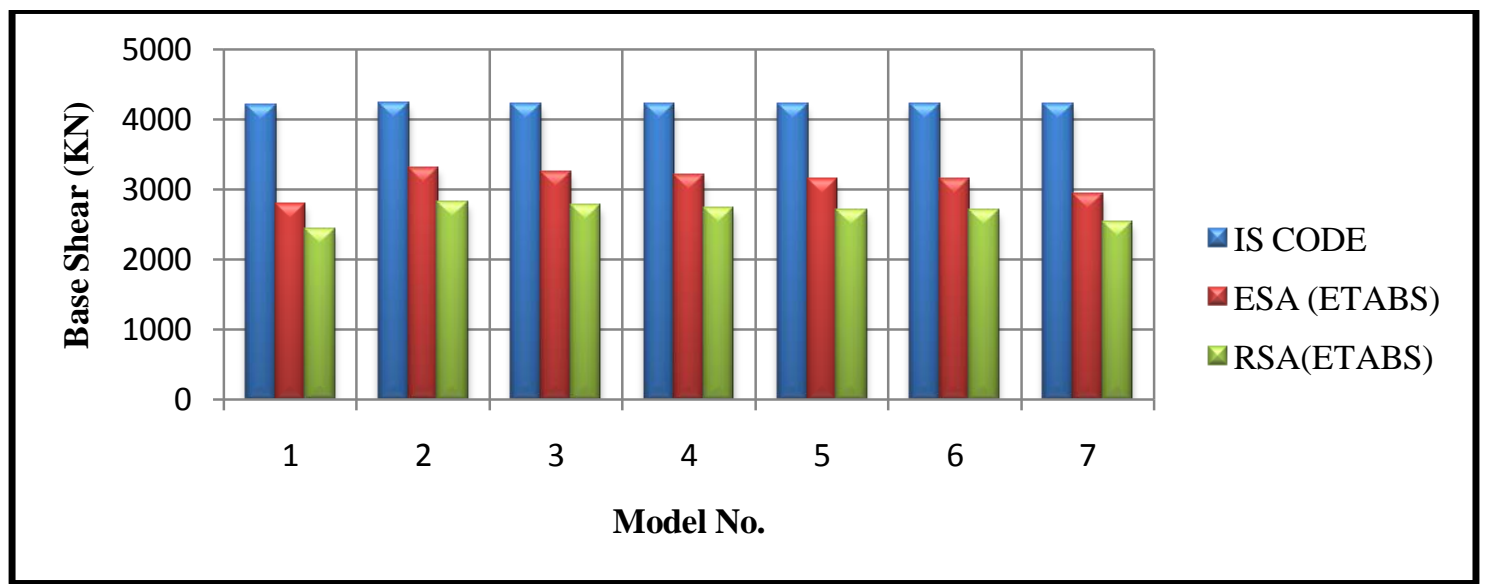

Fig.3 Comparison of Base shear with IS code,ESA and RSA for various building models.

From table 2 and Fig 3 it is clearly evident that When a comparison is made between IS Code, ESA and RSA, IS Code procedure gives considerably higher base shear values than $\operatorname{ESA}($ Etabs) and RSA(Etabs), By considering IS Code(Equivalent Static Procedure) will leads to uneconomical design of structural members and over estimation of structural capacity of members, the percentage of increment of base shear values for IS Code procedure are $33.5 \%, 21.17 \%, 23.0 \%, 24.2 \%, 25.5 \%, 25.5 \%$ and $30.46 \%$ for models 1 to 7 in case of ESA and $42.19 \%, 33.4 \%$, $34.23 \%, 35.14 \%, 36.14 \%, 36.14 \%$ and $40.0 \%$ in case of RSA. ESA and RSA (obtained from ETABS) are showing some consistence variation of base shear values, depending upon the structural configuration of building models.

Table 3: Storey Displacement

\begin{tabular}{|l|l|l|l|l|l|l|l|}
\hline \multicolumn{7}{|l|}{ STOREY DISPLACEMENT } & \\
\hline & MODEL 1 & MODEL 2 & MODEL 3 & MODEL 4 & MODEL 5 & MODEL 6 & MODEL 7 \\
\hline STOREY & Ux & Ux & Ux & Ux & Ux & Ux & Ux \\
\hline 11 & 39.7094 & 35.1228 & 35.2168 & 35.8115 & 36.0386 & 36.0386 & 37.9698 \\
\hline 10 & 38.2828 & 33.4267 & 33.6678 & 34.2116 & 34.5559 & 34.5559 & 36.6071 \\
\hline 9 & 36.1272 & 31.1135 & 31.4772 & 31.9742 & 32.4151 & 32.4151 & 34.5278 \\
\hline 8 & 33.1684 & 28.2022 & 28.6403 & 29.0993 & 29.5945 & 29.5945 & 31.7004 \\
\hline 7 & 29.4952 & 24.7963 & 25.2623 & 25.689 & 26.1947 & 26.1947 & 28.1829 \\
\hline
\end{tabular}




\begin{tabular}{|l|l|l|l|l|l|l|l|}
\hline 6 & 25.2488 & 21.022 & 21.4759 & 21.8709 & 22.3486 & 22.3486 & 24.1404 \\
\hline 5 & 20.5843 & 17.0103 & 17.418 & 17.7761 & 18.193 & 18.193 & 19.6947 \\
\hline 4 & 15.6632 & 12.8937 & 13.2253 & 13.5351 & 13.8635 & 13.8635 & 15.0201 \\
\hline 3 & 10.6757 & 8.8135 & 9.0438 & 9.2883 & 9.508 & 9.508 & 10.2706 \\
\hline 2 & 5.9086 & 4.9543 & 5.0713 & 5.2307 & 5.3373 & 5.3373 & 5.7265 \\
\hline 1 & 1.9226 & 1.6748 & 1.7004 & 1.7628 & 1.7845 & 1.7845 & 1.8998 \\
\hline
\end{tabular}

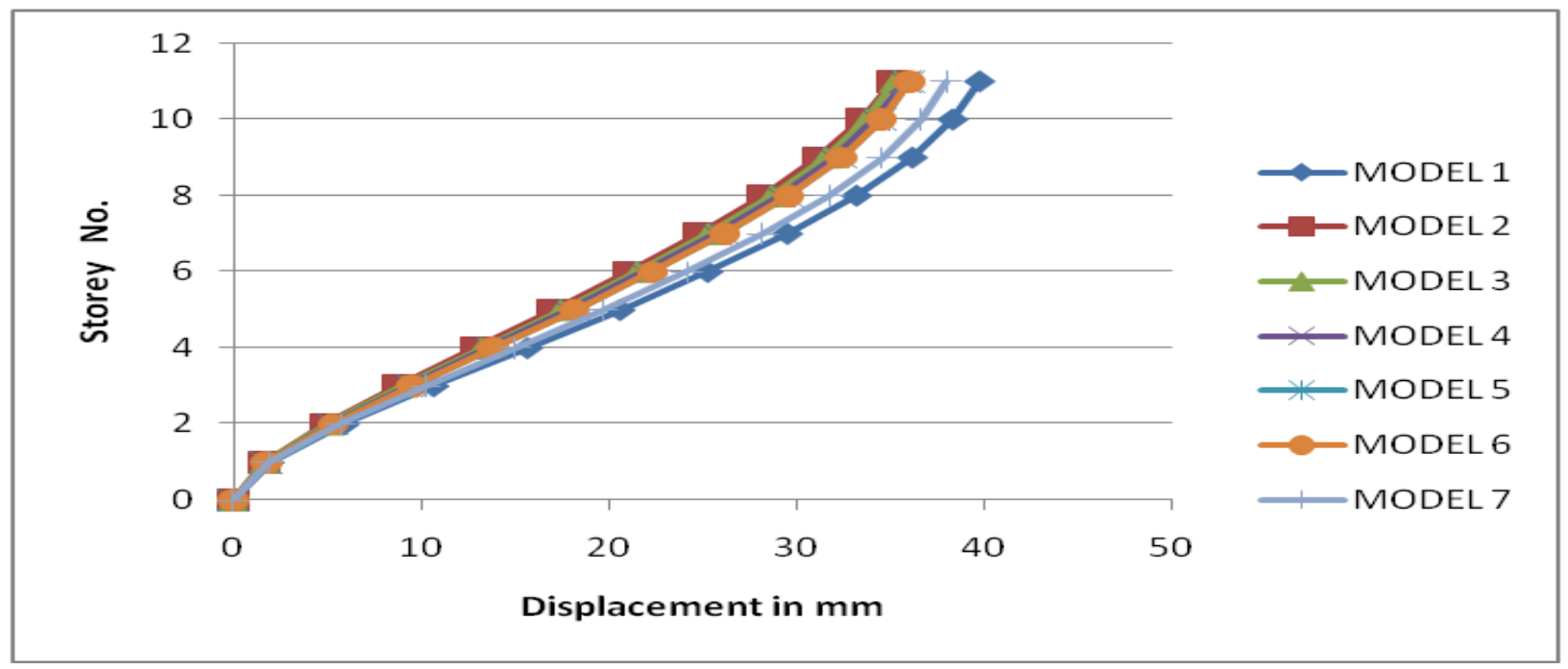

Fig.4 Comparison of storey displacement for different building models

In case of ESA and RSA, model 2 is showing good responses than all other bracings models with maximum decrease in storey displacement at the top storey level is $12 \%$ in case of ESA and 13\% in case of RSA as compared with model 1 .Similarly the percentage of reduction of top storey displacement for model 3 to model 7 are $11.5 \%$,
$10.0 \%, 9.4 \%, 9.4 \%$ and $4.4 \%$ in case of ESA and $11.97 \%$, $10.27 \%, 9.5 \%, 9.5 \%$ and $4.6 \%$.Time history analysis is showing huge displacement values at top storey, because of huge acceleration [refer Table3 and Fig 4 ].

Table 4 : Storey Drift

\begin{tabular}{|l|l|l|l|l|l|l|l|}
\hline \multicolumn{2}{|l|}{ STOREY DRIFT } & & & & & & \\
\hline & MODEL 1 & MODEL 2 & MODEL 3 & MODEL 4 & MODEL 5 & MODEL 6 & MODEL 7 \\
\hline STOREY & Ux & Ux & Ux & Ux & Ux & Ux & Ux \\
\hline 11 & 0.408 & 0.485 & 0.443 & 0.457 & 0.424 & 0.424 & 0.389 \\
\hline 10 & 0.616 & 0.661 & 0.626 & 0.639 & 0.612 & 0.612 & 0.594 \\
\hline 9 & 0.845 & 0.832 & 0.811 & 0.821 & 0.806 & 0.806 & 0.808 \\
\hline 8 & 1.05 & 0.973 & 0.965 & 0.974 & 0.972 & 0.972 & 1.005 \\
\hline 7 & 1.213 & 1.078 & 1.082 & 1.091 & 1.1 & 1.1 & 1.155 \\
\hline 6 & 1.333 & 1.146 & 1.159 & 1.17 & 1.189 & 1.189 & 1.27 \\
\hline 5 & 1.406 & 1.176 & 1.198 & 1.212 & 1.24 & 1.24 & 1.336 \\
\hline 4 & 1.425 & 1.166 & 1.195 & 1.213 & 1.248 & 1.248 & 1.357 \\
\hline 3 & 1.362 & 1.103 & 1.135 & 1.159 & 1.196 & 1.196 & 1.298 \\
\hline 2 & 1.139 & 0.937 & 0.963 & 0.991 & 1.021 & 1.021 & 1.093 \\
\hline 1 & 0.549 & 0.479 & 0.486 & 0.504 & 0.514 & 0.514 & 0.543 \\
\hline
\end{tabular}




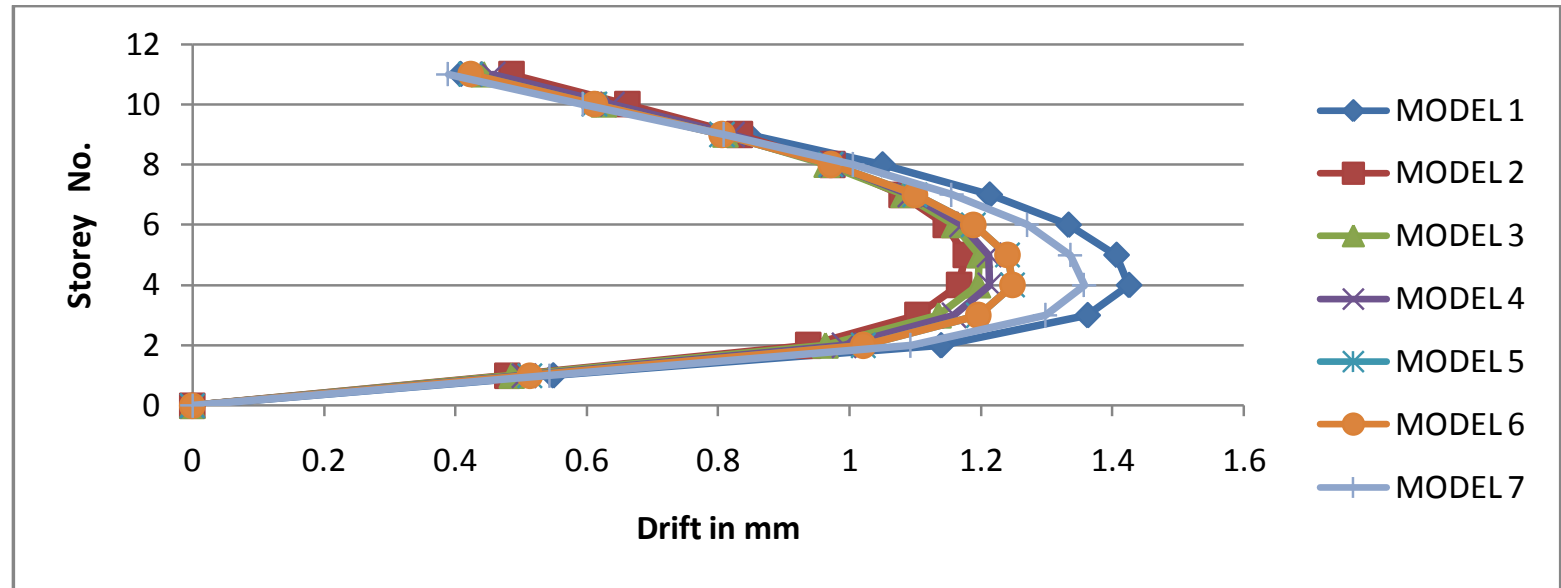

Fig.5 Storey Vs Drift for different building models

From [Fig 5 and Table 4] shows bare frame model has higher Storey Drift values are found within the permissible limit specified by the IS CODE 1893-2002, when the different bracing systems incorporating in models, the storey drift got reduced for ESA and RSA and found in the permissible limits. Model 2 and model 7 are showing much strength and stiffness when subjected to earthquake loading. As from above tables and charts, RSA are showing very much non-linear behaviour and simulating to practical situation which then helps the designer to choose proper analysis procedure.

\section{CONCLUSION}

1. Fundamental time period decreases when the provisions of different types of bracings are considered.

2. The seismic base shear obtained from IS Code is not in a good agreement with the values obtained from ESA and RSA using ETABS.

3.Displacements are found to within the limit in linear static method, linear dynamic and non-linear dynamic analysis.

4. The story drifts are found within the limit as specified by the code IS 1893(Part-1): 2002.

5. $\mathrm{X}$ bracing showing good performance in $\mathrm{x}$ and $\mathrm{y}$ direction hence it can be recommended.

6. When the effect of different types of bracings are provided in different models the storey drift and storey displacement get reduced leading to a safe and stiff model.

7. RSA are showing very much non-linear behaviour and simulating to practical situation which then helps the designer to choose proper analysis procedure.

\section{REFERENCES}

[1] Kulkarni J. G., Kore P. N., Tanawade S. B. " Seismic Response Of Reinforced Concrete Braced Frames" International Journal of Engineering Research and Applications (IJERA) Vol. 3, Issue 4, Jul-Aug 2013, pp.1047-1053.

[2] A.R. Khaloo \& M. Mahdi Mohseni, "Nonlinear Seismic Behaviour of RC Frames with RC Braces" Asian Journal of Civil Engineering, Vol. 9, No. 6, 2008.
[3] S. I. Khan, Prof. P. O. Modani "Seismic Retrofitting of RC Building by Using Different Bracing Systems" International Journal of Engineering Research \& Technology (IJERT) Vol. 2 Issue 7, July - 2013

[4] Pankaj Agarwal, Manish Shrikhande: "Earthquake Resistant Design of Structures", PHI Learning Private Limited, 2011

[5] Patil S.S., Aland S.S., Kore P.N. "Seismic Response of Concentrically Braced Reinforced Concrete Frames", International Journal of Scientific and Engineering Research, Volume 4, Issue7, July 2013 Edition

[6] IS 1893(Part-I) 2002: Criteria for Earthquake Resistant Design of Structures, Part-I General Provision and Buildings (Fifth Revision). Bureau of Indian Standards, New Delhi.

[7] IS 456: 2000. "Indian Standard Code of Practice for plain and reinforced Concrete", Bureau of Indian Standards, New Delhi. 